\title{
Lithium Isotope Separation on Complex Formation I. Equilibrium Study
}

\author{
Shigeru Yamashita and Teruo Hayakawa*
}

(Received June 5, 1963)

\begin{abstract}
Lithium isotope separation on molecular complex formation has been studied in lithium chloride- 1,4-dioxane systems. The complex shows an absorption maximum at $270 \mathrm{~m} \mu$, and the molar ratio $\mathrm{LiCl} /$ dioxane in the complex has been found to be $1: 1$. The isotope ratio has been determined by a mass spectrometer using a surface ionization ion source. The results show that $\mathrm{Li}$ is enriched in the complex and the single stage separation factor is 1.026 in equilibrium at $100^{\circ} \mathrm{C}$. The separation of lithium isotopes seems to occur during the isotope exchange reaction between LiCl-dioxane complex and uncomplexed $\mathrm{LiCl}$.
\end{abstract}

\section{Introduction}

The separation of lithium isotopes ${ }^{6} \mathrm{Li}$ and ${ }^{7} \mathrm{Li}$ has been studied by some workers with interest in nuclear science and geochemistry. The enrichment of lithium isotopes by ion-exchange resin has been reported in some papers ${ }^{1,2,3)}$, and the separation of lithium isotopes has been studied by countercurrent electromigration ${ }^{4}$. The isotope separation has also been observed in the precipitation of lithium carbonate from ammoniac alkaline solution ${ }^{5)}$, and in the reaction of metallic lithium with alkylhalogenides $^{6}$. Other kinds of reactions of lithium compounds might be effective for the separation of lithium isotopes.

In the case of boron isotope separation, the complexes formed between boron halogenides and ether compounds have been used and it has been shown that there is an enrichment of ${ }^{10} \mathrm{~B}$ in these complexes. For example, in the $\mathrm{BF}_{3}$-anisole system, the single stage separation factor

$$
a=\frac{{ }^{10} \mathrm{BF}_{3} \text {. anisole (liq.) } /{ }^{11} \mathrm{BF}_{3} \text {. anisole (liq.) }}{{ }^{10} \mathrm{BF}_{3} \text { (gas) } /{ }^{11} \mathrm{BF}_{3} \text { (gas) }}
$$

has been found to be 1.039 at $0^{\circ} \mathrm{C}^{7}$.

Since lithium halides form molecular complexes with dioxane molecules which have two ether $\mathrm{C}-\mathrm{O}-\mathrm{C}$ bonds $^{8}$, the present authors expected a similar isotope separation effect to occur in the formation of lithium halide-dioxane complex as in the $\mathrm{BF}_{3}$-anisole system. In this paper, lithium chloride was used as the lithium halide, and some hitherto unpublished properties of the lithium chloridedioxane complex, together with the results of the equilibrium study of the isotope exchange reaction of lithium in the lithium chloride-dioxane system are reported.

\section{Experimental}

\subsection{Materials.}

Lithium chloride (manufactured by Mitsuwa Pure Chemicals) and 1,4-dioxane (manufactured by Wako Pure Chemicals) of extra pure grade were used without further purification.

* Department of Chemistry, College of General Education, University of Osaka Prefecture, Mozu-Umemachi, Sakai, Osaka. 


\subsection{Mass Spectrometer.}

The mass spectrometer used in the present work is a $90^{\circ}$ sector type small instrument (the radius of curvature of the analyser tube is $130 \mathrm{~mm}$ ) to which a surface ionization ion source of the triple filament type ${ }^{9,10)}$ was attached. Magnetic scanning was used for ion selection, and a d.c. amplifier of the conventional type was used for ion detection.

\subsection{Procedure.}

The lithium chloride-dioxane complex was prepared as follows: In a dried, water-tight flask powdered lithium chloride and large excess of 1,4-dioxane were introduced and stirred at $100^{\circ} \mathrm{C}$. Lithium chloride was dissolved in dioxane to saturation, the lithium chloride-dioxane complex being formed in the dioxane solution. In order to isolate the complex, the hot solution was rapidly cooled to induce crystallization of the complex in the form of white hygroscopic needles.

A gravimetric method was used for determination of the molar ratio of the two components in lithium chloride-dioxane complex. A small amount of weighed, solvent-free complex was heated at $135^{\circ} \mathrm{C}$, so that the complex decomposed into the components, and the dioxane formed was pumped off. Since the residue was lithium chloride, the molar ratio of the complex components could then be determined.

The absorption curve of the complex was measured by means of a Hitachi UV-spectrophotometer. The sample solution used for absorption measurement was a complex-saturated dioxane, the backgrund absorption of dioxane being subtracted. However, the molar extinction coefficient of the absorption band could not be obtained because the complex crystals were very hygroscopic and partially dissociated into their components in the solvent.

For the equilibrium study of the lithium isotope exchange reaction, the lithium isotope ratio ${ }^{7} \mathrm{Li}$ $/{ }^{6} \mathrm{Li}$ in the complex was measured by the above-mentioned mass spectrometer. The details of the lithium isotope ratio measurements were previously reported by one of the present authors ${ }^{9}$.

\section{Results and Discussion}

\subsection{Absorption curve of the complex}

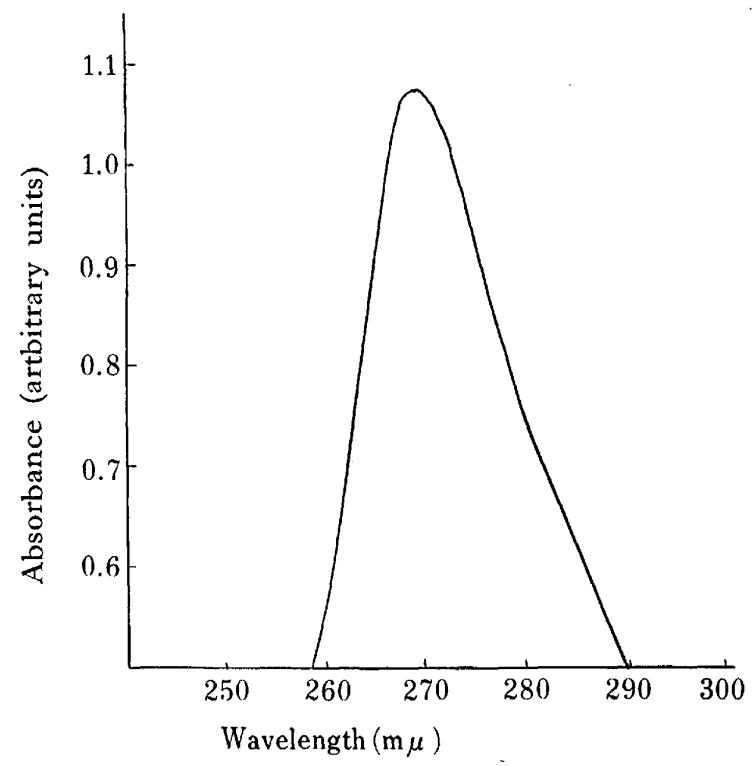

Fig. 1. Absorption curve of the lithiumchloridedioxane molecular complex. 
The absorption curve obtained is shown in Fig. 1. Apparently, the complex has an absorption maximum at $270 \mathrm{~m} \mu$. The absorption band of the complex seems to be a charge transfer absorption band theoretically explained by Mulliken ${ }^{11)}$. Similar complexes have been found in aluminium chloride-benzene and ferric chloride-cyclohexane systems ${ }^{12,13}$.

Table 1. Determination of the molar composition of the lithium chloride-1,4-dioxane molecular complex.

\begin{tabular}{c|r|r|c|}
\hline \hline $\begin{array}{c}\text { Total weight of complex } \\
(\mathrm{mg})\end{array}$ & $\begin{array}{r}\text { Weight of } \mathrm{LiCl} \text { component } \\
(\mathrm{mg})\end{array}$ & \multicolumn{2}{|c|}{$\begin{array}{c}\text { Weight of the LiCl component } \\
\text { Total weight of the complex }\end{array}$} \\
\hline 254 & 86 & 0.338 & 0.324 \\
426 & 133 & 0.313 & calculated from $1: 1$ composition \\
\hline
\end{tabular}

\subsection{Molar ratio of the complex components}

The results of the gravimetric analysis of the complex are given in Table 1, which shows that the complex is composed of lithium chloride and dioxane in equimolar amounts. In the complex, the dioxane is weakly bonded to lithium chloride and easily pumped off by evacuation at $25^{\circ} \mathrm{C}$. When cooled at $0^{\circ} \mathrm{C}$, the complex is comparatively stable since the dioxane component is not so volatile at this temperature.

\subsection{Isotope separation on complex formation}

As shown in Fig. 2 and Table 2, the time-variation of the isotope ratio ${ }^{7} \mathrm{Li} /{ }^{6} \mathrm{Li}$ in the complex was observed as excess lithium chloride was added to the dioxane-lithium chloride system. Although the isotope ratio ${ }^{7} \mathrm{Li} /{ }^{6} \mathrm{Li}$ in the complex increases with time and reaches an equilibrium value, the change is very slow during the initial stage which lasts about one hour, which indicates that the dissolution of lithium chloride in dioxane and lithium chloride-dioxane complex formation occurring in the initial stage are not so effective for lithium isotope separation.

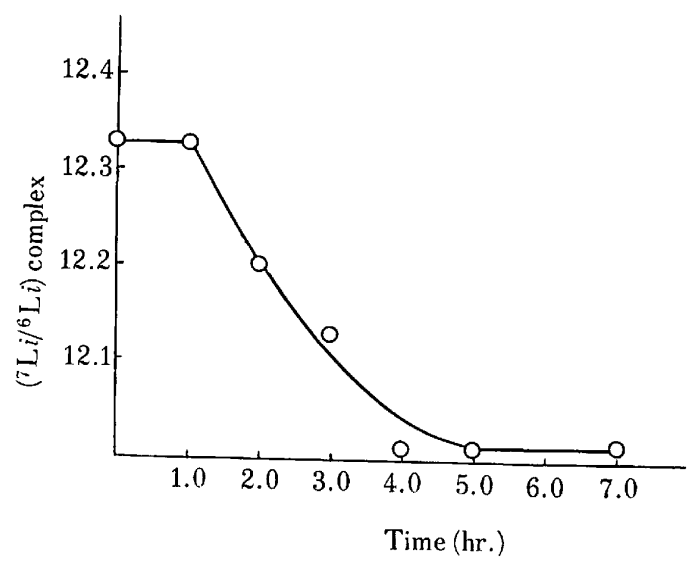

Fig. 2. Time-variation of the isotope ratio $\left({ }^{7} \mathrm{Li} /{ }^{6} \mathrm{Li}\right)$ complex in the presence of undissolved lithium chloride.

Reaction temperature: $100^{\circ} \mathrm{C}$. 
Table 2. Time-variation of the isotope ratio $\left({ }^{7} \mathrm{Li} /{ }^{6} \mathrm{Li}\right)$ complex and the rate of separation in the presence of undissolved lithium chloride.

$\left({ }^{7} \mathrm{Li} /{ }^{6} \mathrm{Li}\right)$ solution $\div 12.33 \pm 0.03$

Reaction temperature: $100^{\circ} \mathrm{C}$.

\begin{tabular}{c|c|c}
\hline \hline $\begin{array}{c}\text { Time } \\
(\text { hr. })\end{array}$ & $\left({ }^{7} \mathrm{Li} /{ }^{6} \mathrm{Li}\right)_{\text {complex }}$ & $\frac{\left({ }^{6} \mathrm{Li} /{ }^{7} \mathrm{Li}\right)_{\text {complex }}}{\left({ }^{6} \mathrm{Li} /{ }^{7} \mathrm{Li}\right)_{\text {solution }}}$ \\
\hline 1.0 & $12.33 \pm 0.02$ & $1.000 \pm 0.001$ \\
2.0 & $12.20 \pm 0.03$ & $1.011 \pm 0.001$ \\
3.0 & $12.13 \pm 0.04$ & $1.017 \pm 0.001$ \\
4.0 & $12.01 \pm 0.04$ & $1.026 \pm 0.001$ \\
5.0 & $12.01 \pm 0.04$ & $1.026 \pm 0.001$ \\
7.0 & $12.02 \pm 0.04$ & $1.026 \pm 0.001$ \\
\hline
\end{tabular}

At the equilibrium state the observed single stage separation factor at $100^{\circ} \mathrm{C}$

$$
\begin{aligned}
& =\frac{{ }^{6} \mathrm{LiCl} \cdot \text { dioxane } /{ }^{7} \mathrm{LiCl} \cdot \text { dioxane }}{\left({ }^{6} \mathrm{LiCl} /{ }^{7} \mathrm{LiCl}\right)_{\text {solution }}} \\
& =\frac{\left({ }^{7} \mathrm{Li} /{ }^{6} \mathrm{Li}\right)_{\text {solution }}}{\left({ }^{7} \mathrm{Li} /{ }^{6} \mathrm{Li}\right)_{\text {complex }}}
\end{aligned}
$$

is 1.026 , which is of a comparable order of magnitude to the separation factor 1.03 found in the $\mathrm{BF}_{3}$-ether system. Here, the value of $\left({ }^{7} \mathrm{Li} /{ }^{6} \mathrm{Li}\right)$ solution in the above equation was determined to be $12.33 \pm 0.03$, which is equal to the $\left({ }^{7} \mathrm{Li} /{ }^{6} \mathrm{Li}\right)$ value of the added sample of lithium chloride. It is quite natural since there is large excess of undissolved, solid lithium chloride in the reaction system. The observed change of the separation factor with time is shown in Fig. 3 and Table 2.

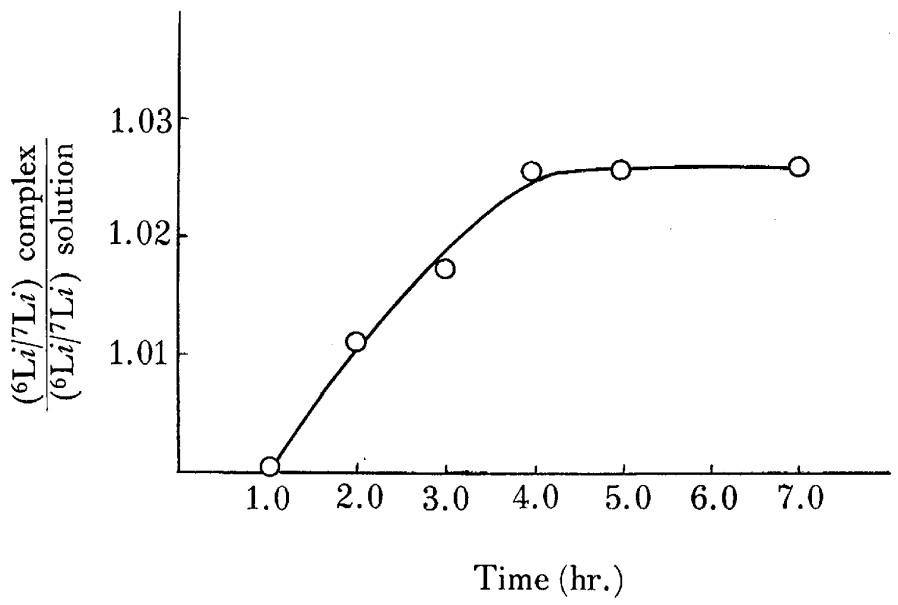

Fig. 3. Time-variation of the rate of separation in lithium chloride-dioxane system.

Reaction temperature: $100^{\circ} \mathrm{C}$.

In addition, the time-variation of the lithium isotope ratio in the complex was measured when the excess undissolved lithium chloride was removed from the system one hour after the reaction started, at which point the separation of the lithium isotope is not measureable as already described. 
The results shown in Fig. 4 and Table $3^{*}$ indicate that, after the removal of undissolved lithium chloride, the isotopic exchange reaction of lithium continues until equilibrium is reached.

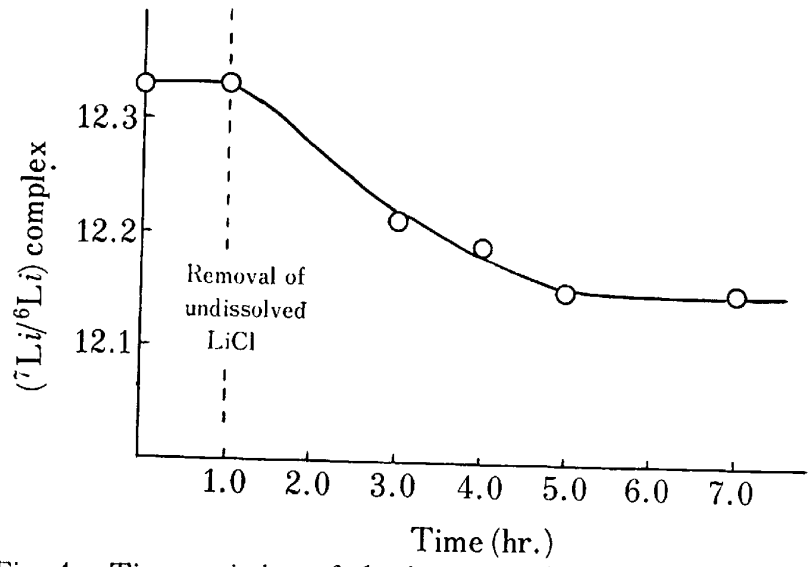

Fig. 4. Time-variation of the isotope ratio $\left({ }^{7} \mathrm{Li} /{ }^{6} \mathrm{Li}\right)$ complex when undissolved $\mathrm{LiCl}$ was removed.

Reaction temperature: $100^{\circ} \mathrm{C}$.

Table 3. Time-variation of the isotope ratio $\left({ }^{7} \mathrm{Li} /{ }^{6} \mathrm{Li}\right)$ complex under removal of undissolved lithium chloride.

Reaction temperature: $100^{\circ} \mathrm{C}$.

\begin{tabular}{c|c}
\hline $\begin{array}{c}\text { Time } \\
(\mathrm{hr} .)\end{array}$ & $\left({ }^{7} \mathrm{Li} /{ }^{6} \mathrm{Li}\right)$ complex \\
\hline 1.0 & $12.33 \pm 0.02$ \\
(Undissolved lithium chloride was removed.) & $12.21 \pm 0.02$ \\
3.0 & $12.19 \pm 0.01$ \\
4.0 & $12.15 \pm 0.01$ \\
5.0 & $12.15 \pm 0.03$ \\
7.0 & \\
\hline
\end{tabular}

The time-variation of the isotope ratio $\left({ }^{7} \mathrm{Li} /{ }^{6} \mathrm{Li}\right)_{\text {complex }}$ shown in Fig. 4 and Table 3 is similar in nature to that shown in Fig. 2 and Table 2, and in both cases the isotope exchange equilibrium at $100^{\circ} \mathrm{C}$ is attained about 4 hours after the mixing of lithium chloride and dioxane.

Either or both of the following two processes might be taken into consideration for the isotope separation reaction of lithium observed in the present experiments;

(i) the dissolution of lithium chloride in dioxane,

(ii) the molecular complex formation and the succeeding isotope exchange reaction of lithium.

If (i) is the rate-determining step of the separation of lithium isotopes in question, the variation in the lithium isotope ratio with time would not be observed after the removal of excess, undissolved lithium chloride, and this is inconsistent with the experimental results shown in Fig. 4 and Table 3 .

* In the absence of undissolved lithium chloride, the equilibrium value of the isotope ratio $\left({ }^{7} \mathrm{Li} /{ }^{6} \mathrm{Li}\right)$ complex is higher than that obtained in the presence of undissolved lithium chloride. This stems from the situation that the isotope ratio $\left({ }^{7} \mathrm{Li} /{ }^{6} \mathrm{Li}\right)$ solution in the absence of excess lithium chloride is larger than that observed in the presence of excess lithium chloride, since in the latter case the isotope ratio $\left({ }^{7} \mathrm{Li} /{ }^{6} \mathrm{Li}\right)$ solution is practically equal to the isotope ratio $\left({ }^{7} \mathrm{Li} /{ }^{6} \mathrm{Li}\right)$ in the excessively added lithium chloride. 
Thus, we may conclude that the separation of lithium isotopes occurs from step (ii) by the following mechanism

$\begin{array}{ccc}\mathrm{LiCl} \text { (solid) } & \longleftarrow & \mathrm{LiCl} \text { (solution) } \\ \mathrm{LiCl} \text { (solution) }+ \text { dioxane } & \longleftarrow & \mathrm{LiCl} \cdot \text { dioxane } \\ { }^{6} \mathrm{LiCl} \text { (solution) }+{ }^{7} \mathrm{LiCl} \cdot \text { dioxane } & \longleftarrow & { }^{7} \mathrm{LiCl} \text { (solution) }+{ }^{6} \mathrm{LiCl} \cdot \text { dioxane }\end{array}$

Since the separation factor $a$ is found to be 1.026 , the lighter isotope ${ }^{6} \mathrm{Li}$ is enriched in the molecular complex, and this resembles the ${ }^{10} \mathrm{~B}$ enrichment in boron fluoride-ether systems ${ }^{7}$.

The lighter isotope enrichment in these molecular complexes suggests that ${ }^{6} \mathrm{LiCl}$-dioxane, ${ }^{10} \mathrm{BF}_{3}$ -anisole are more stable than the isotopic complexes ${ }^{7} \mathrm{LiCl}$-dioxane and ${ }^{11} \mathrm{BF}_{3}$-anisole, respectively. There must be some differences in the heat of formation between these isotopic molecular complexes, but the difference is supposed to be very small and it may be considerably difficult to measure the differences in the heat of formation.

For further elucidation of the isotope separation of lithium occurring in the molecular complex formation, a kinetic study of the isotopic exchange reaction of lithium (Process 3 ) is in progress using Li-enriched lithium chloride as a tracer. The results of this will be published in the succeeding paper.

\section{Acknowledgements}

The authors wish to express their hearty thanks to Emelitus Professor N. Sasaki of Kyoto University and Professor T. Titani of Tokyo Metropolitan University for their constant encouragement.

\section{References}

1) T. I. Taylor and H. C. Urey, J. Chem. Phys., 5, 597 (1937).

2) D. A. Lee and G. M. Begun, J. Am. Chem. Soc., 81, 2332 (1959); D. A. Lee, ibid., 83, 1801 (1961).

3) R. Lindner and T. Bergdahl, Z. Elektrochem., 64, 919 (1960).

4) J. Perie, M. Chemla et M. Gignoux, Bull. Soc. Chim. France, (1961) 1249.

5) S. Taniguchi, I. Shionoya, O. Toyama and T. Hayakawa, Bull. Univ. Osaka Pref., A9, 59 (1960).

6) W. Herzog, W. Betz and A. Neubert, Z. Naturforschg., 16a, 242 (1962).

7) A. A. Palko, R. M. Healy and L. Landau, J. Chem. Phys., 28, 214 (1958).

8) H. Rheinboldt, A. Luyken and H. Schmittmann, J. Prak. Chem., N.F. 148, 82 (1937).

9) S. Taniguchi, O. Toyama and T. Hayakawa, Mass Spectroscopy, 10, 91 (1962).

10) S. Taniguchi, O. Toyama and T. Hayakawa, ibid., 10, 100 (1962).

11) R. S. Mulliken, J. Am. Chem. Soc., 74, 811 (1952).

12) D. D. Eley and P. J. King, J. Chem. Soc., (1952), 4972.

13) D. S. Brackman and P. H. Plesch, J. Chem. Soc., (1953), 1289. 